\title{
Tropical-Forest Biomass Estimation at X-Band From the Spaceborne TanDEM-X Interferometer
}

\author{
Robert Treuhaft, Fabio Gonçalves, João Roberto dos Santos, Michael Keller, Michael Palace, \\ Søren N. Madsen, Franklin Sullivan, and Paulo M. L. A. Graça
}

\begin{abstract}
This letter reports the sensitivity of X-band interferometric synthetic aperture radar (InSAR) data from the first dual-spacecraft radar interferometer, TanDEM-X, to variations in tropical-forest aboveground biomass (AGB). It also reports the first tropical-forest AGB estimates from TanDEM-X data. Tropical forests account for about $50 \%$ of the world's forested biomass and play critical roles in the control of atmospheric carbon dioxide by emission through deforestation and uptake through forest growth. The TanDEM-X InSAR data used in this analysis were taken over the Tapajós National Forest, Pará, Brazil, where field measurements from 30 stands were acquired. The magnitude of the InSAR normalized complex correlation, which is called coherence, decreases by about $25 \%$ as AGB increases from 2 to $430 \mathrm{Mg}-\mathrm{ha}^{-1}$, suggesting more vertically distributed return-power profiles with increasing biomass. Comparison of InSAR coherences to those of small-spot $(15 \mathrm{~cm})$ lidar suggests that lidar penetrates deeper into the canopies than InSAR. Modeling InSAR profiles from InSAR coherence and lidar profiles yields an estimate of $0.29 \mathrm{~dB} / \mathrm{m}$ for the $\mathrm{X}$-band extinction coefficient relative to that of lidar. Forest AGB estimated from InSAR observations on 0.25-ha plots shows RMS scatters about the field-estimated AGB between 52 and

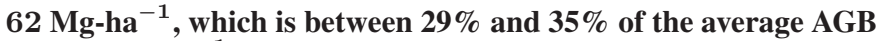

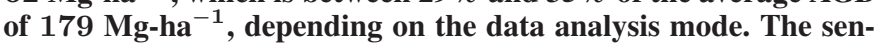
sitivity and biomass-estimation performance suggest the potential of TanDEM-X observations to contribute to global tropical-forest biomass monitoring.
\end{abstract}

Index Terms-Biomass, interferometric synthetic aperture radar (InSAR), lidar, tropical forest.

Manuscript received March 21, 2014; revised May 20, 2014; accepted June 4, 2014

R. Treuhaft and S. N. Madsen are with the Jet Propulsion Laboratory, California Institute of Technology, Pasadena, CA 91109 USA (e-mail: robert. treuhaft@jpl.nasa.gov; soren.n.madsen@jpl.nasa.gov).

F. Gonçalves is with the Woods Hole Research Center, Falmouth, MA 02540 USA (e-mail: fgoncalves@whrc.org).

J. R. dos Santos is with the Instituto Nacional de Pesquisas Espaciais, 12227 010 Sao Jose dos Campos-SP, Brazil (e-mail: jroberto@dsr.inpe.br).

M. Keller is with the U.S. Department of Agriculture Forest Service, International Institute of Tropical Forestry, San Juan, PR 00926-1119 USA and also with the Empresa Brasileira de Pesquisa Agropecuária (EMBRAPA) Satellite Monitoring, 13070-115 Campinas-SP, Brazil, and the University of New Hamphsire, Durham, NH 03824 USA (e-mail: mkeller. co2@gmail.com).

M. Palace and F. Sullivan are with the University of New Hampshire, Durham, NH 03824 USA (e-mail: palace@guero.sr.unh.edu; fsulliva@gmail. com).

P. M. L. A. Graça is with the Instituto Nacional de Pesquisas da Amazônia, 69067-375 Manaus-AM, Brazil (e-mail: pmlag@inpa.gov.br).

Color versions of one or more of the figures in this paper are available online at http://ieeexplore.ieee.org.

Digital Object Identifier 10.1109/LGRS.2014.2334140

\section{INTRODUCTION}

$\mathbf{T}$ ROPICAL forests account for about 50\% of the world's remaining forested biomass [1]. However, there are large uncertainties associated with the estimates of tropical-forest biomass stocks and the change in those stocks [2], [3]. Tropical deforestation contributes about $15 \%$ of anthropogenic carbon emissions to the atmosphere [3]. However, both primary and secondary tropical forests are also growing, and a recent synthesis has suggested that $70 \%$ of the terrestrial carbon sink resides in tropical forests [4]. Global monitoring of forest aboveground biomass (AGB) with subhectare $\left(1 \mathrm{ha}=10^{4} \mathrm{~m}^{2}\right)$ resolution will facilitate the understanding of carbon storage and its flux between forests and the atmosphere [5], [6]. One of the most promising approaches to global remote sensing of AGB is to measure attributes of the forest structure, such as average height, and estimate AGB from those attributes.

The structural attribute measured with interferometric synthetic aperture radar (InSAR) is the Fourier transform of the vertical radar power profile coming from the forest [7], which has been linked to the ground-measured leaf area density profile (see [8, Fig. 7]). This letter presents the sensitivity of the InSAR Fourier transform to tropical-forest AGB, as well as the first AGB estimates from structural Fourier transforms, from the first dual-spacecraft interferometer, TanDEM-X [9]. It also compares the InSAR Fourier transforms with those of small-footprint lidar, suggesting that InSAR at the X-bandwavelength $(\lambda=0.031 \mathrm{~m})$-is more attenuated by the forest than lidar. X-band noninterferometric power is generally observed to be insensitive to forest AGB $>50 \mathrm{Mg}$-ha $^{-1}$, e.g., [10], and radar power at the C-band and the X-band is usually deemed useless for biomass estimation. In contrast, the X-band interferometric complex correlation reported here appears to have sensitivity to much higher AGBs up to $\approx 300 \mathrm{Mg}$-ha $^{-1}$, which is typical of tropical forests. It exhibits reasonable singlebaseline estimation performance. This study suggests that $\mathrm{X}$-band spaceborne InSAR should be further evaluated for its potential to contribute to an AGB estimation system, either as a standalone or with other sensors.

\section{Field Site in the BRaZilian Amazon}

The Tapajós National Forest is located along highway BR-163, which is $\approx 50 \mathrm{~km}$ south of Santarem, Pará, in the central Brazilian Amazon. The climate is tropical humid (Köppen Am), with a mean annual temperature of $25^{\circ} \mathrm{C}$ and mean annual rainfall of $1900 \mathrm{~mm}$ with a five-month dry season $\left(<100 \mathrm{~mm}\right.$ month $\left.^{-1}\right)$ between July and November [11]. The vegetation is dense upland tropical moist forest. Field 
measurements were taken in September 2010 on 30 plots $(50 \mathrm{~m} \times 50 \mathrm{~m}=0.25 \mathrm{ha})$, with $\mathrm{AGB}$ ranging from 2 to

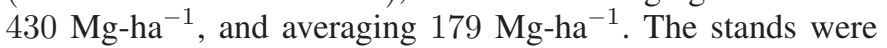
primary and secondary forests and included some selective logging sites. The field plots were thus representative of the variety of the area observed by TanDEM-X and lidar. Field measurements for each tree included total height, height-tobase-of-crown, tree diameter, species (to estimate wood density), crown dimensions, and location. The diameter, height, and wood density were used with allometric equations [12] to estimate AGB. The heights and crown dimensions were used to estimate field leaf area density profiles [8]. Plots were geolocated with submeter accuracy using differential Global Positioning System and a total station.

\section{TANDEM-X INSAR DATA AND LIDAR DATA}

The TanDEM-X interferometer consists of two spacecraft separated by a baseline, $\vec{B}$, e.g., [13]. The output of the interferometer is obtained by cross-correlating (cross multiplying) the complex signals - amplitude and phase — from each spacecraft. The normalized complex correlation of the TanDEM-X data, i.e., $\gamma_{I}\left(\alpha_{z}\right)$, is the normalized Fourier transform of the radar power profile, i.e., $g(z)$, in the vertical direction for vertical interferometric frequency $\alpha_{z}$, which is a function of $\vec{B}$. Thus

$$
\gamma_{I}\left(\alpha_{z}\right)=\frac{\int_{0}^{\infty} g(z) \exp \left[i \alpha_{z} z\right] d z}{\int_{0}^{\infty} g(z) d z} \text { with } \alpha_{z} \equiv \frac{2 \pi B_{\perp}}{\lambda r \sin \theta}
$$

where $B_{\perp}$ is the component of the baseline perpendicular to the radar line of sight, $\lambda$ is the radar wavelength, $r$ is the range from the radar to the ground location, and $\theta$ is the incidence angle. Due to $\alpha_{z}$ 's dependence on $\vec{B}$, InSAR gives one Fourier transform, i.e., $\gamma_{I}\left(\alpha_{z}\right)$, of the vertical power distribution per baseline. In this letter, the radar power $g(z)$ is from horizontal transmit and receive polarization only. In general, the power profile $g(z)$ is not directly measureable. From the measured $\gamma_{I}\left(\alpha_{z}\right)$, one knows only $g(z)$ 's Fourier transform at $\alpha_{z}$. Two often-cited properties of $\gamma_{I}\left(\alpha_{z}\right)$ are that, with increasing vertical extent of $g(z)$, its amplitude (coherence) decreases, and its phase increases, e.g., [13] and [14]. Fig. 1 shows an image of TanDEM-X coherence for a part of the Tapajós test site with dimensions of approximately $47 \times 18 \mathrm{~km}$ acquired in September 2011. The coherence of each point is calculated using a movingwindow average of the complex interferometric cross correlation over $50 \mathrm{~m} \times 50 \mathrm{~m}$ [14]. With a 1.4-m fundamental resolution in the range (horizontal) direction and $2.5-\mathrm{m}$ resolution in the along-track (vertical) direction, each point corresponds to about 700 fundamental pixels. The complex-correlation Fourier frequency of $\approx 0.086 \mathrm{rad} / \mathrm{m}$ was realized with a baseline of 180 $\mathrm{m}$, a spacecraft altitude of about $514 \mathrm{~km}$, and an incidence angle of $40^{\circ}$, which varied over the image by about $1^{\circ}$. The darker green area, signifying lower coherence, in the center of the image is mostly mature forests, whereas, for example, the lighter areas to the east of the BR-163 highway (linear feature on the right side of the image) are recently cleared areas, pastures, agriculture, or young regrowth. Note that InSAR swaths can be a few kilometers up to 100 s of kilometers, and

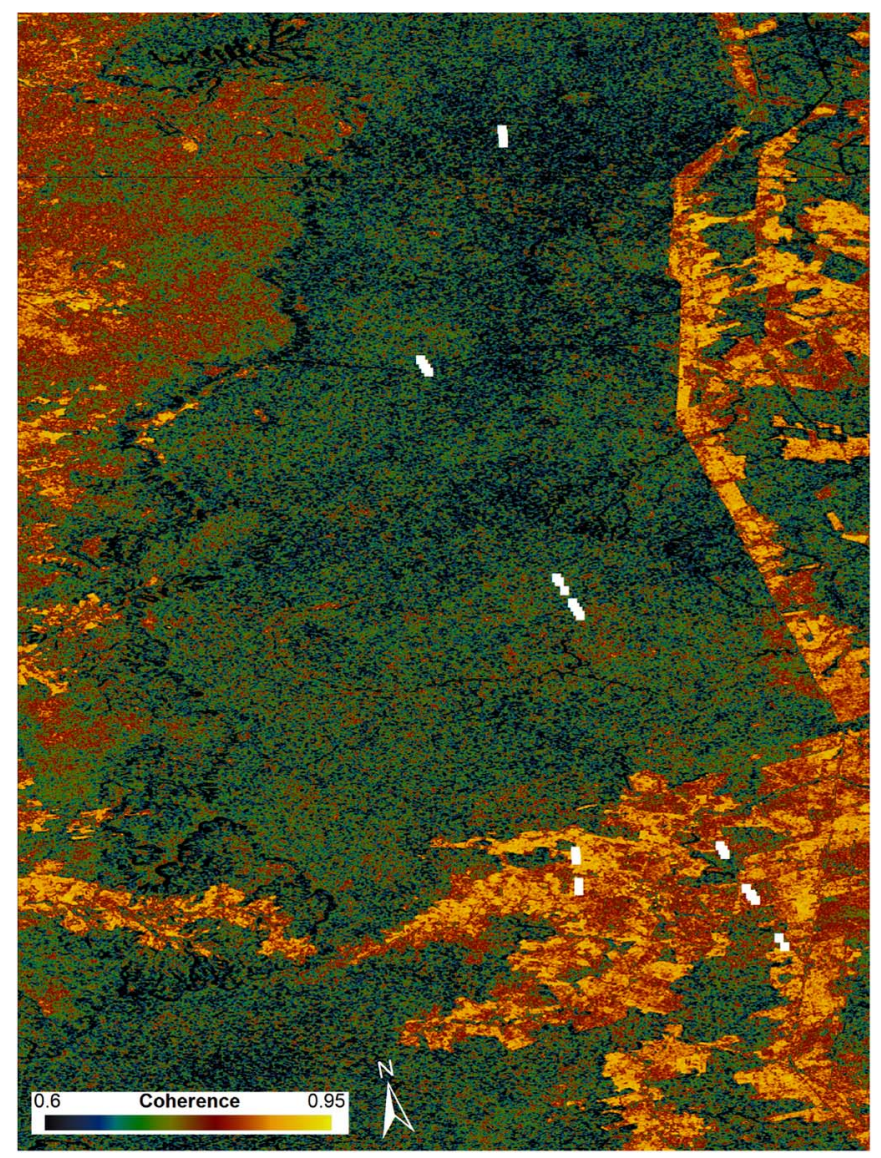

Fig. 1. InSAR Coherence from TanDEM-X, the magnitude of (1), over a $47 \mathrm{~km}$ (vertical) $\times 18 \mathrm{~km}$ area of the Tapajós test site. The center of the image is at $3.0114^{\circ} \mathrm{S}$ and $54.9900^{\circ} \mathrm{W}$. The white dots indicate the locations of the 30 sites. Coherence scale is indicated along with true north. The spacecraft trajectory points downward parallel to the long side.

Fig. 1 was taken from about 7 seconds of a single pass of the dual-spacecraft system, with an 18-km swath.

The other principal structural measurement, lidar, e.g., [15], with only $\approx 100-\mathrm{m}$ swaths realized from space [16] and up to few-kilometer swaths from airborne platforms has consequently restricted spatial coverage. Coverage of lidar at $\approx 1 \mu$ wavelengths is particularly restricted in the tropics due to clouds [17]. However, lidar measures essentially all Fourier frequencies of the infrared power profile, which it directly detects by measuring the roundtrip laser propagation times from the sensor to the forest and back. Previous work suggests that this infrared power profile, which is called the lidar "waveform," is closely related to the leaf area density profile, e.g., [8] and [18]. The lidar data used in this study were acquired by GEOID Ltda. in August 2012 using an Optech 3100 EA instrument flown at approximately $600 \mathrm{~m}$ with a $10^{\circ}$ field of view, a small footprint $(\approx 15 \mathrm{~cm})$, and a $30 \%$ overlap between adjacent swaths. For each lidar shot, the first and the last return were recorded, with approximately 25-39 returns per $\mathrm{m}^{2}$. For comparison to TanDEM-X, waveforms were synthesized from all returns from 19 of the 30 field-measured $50 \mathrm{~m} \times 50 \mathrm{~m}$ plots that fell within the 2000 ha of lidar coverage. Fourier transforms of the lidar waveforms were taken at the same $0.086-\mathrm{rad} / \mathrm{m}$ frequency as that which generated the InSAR coherence in Fig. 1, as in (2). 


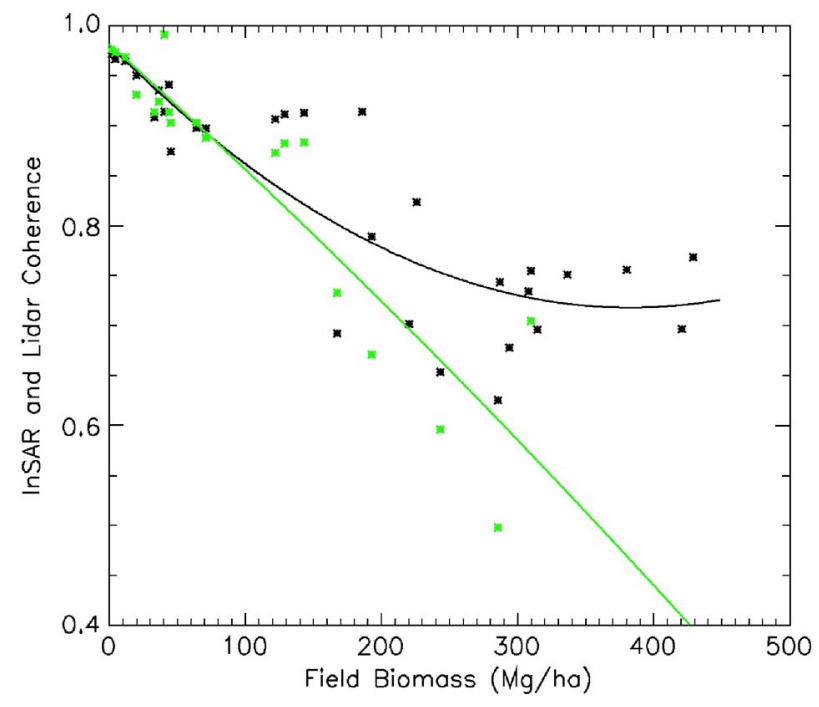

Fig. 2. InSAR coherence-magnitude of (1)-from TanDEM-X in black for 30 field locations versus field-estimated AGB. The black curve is a secondorder polynomial fit of TanDEM-X coherence versus AGB. Lidar coherencemagnitude of (2) - is in green, with the green curve a second-order polynomial fit. The vertical wavelength of both InSAR and lidar is $73 \mathrm{~m}$.

\section{TANDEM-X SENSITIVITY TO TROPICAL-FOREST BIOMASS}

Fig. 2 shows the InSAR coherence in black - the magnitude of $\gamma_{I}\left(\alpha_{z}\right)$ in (1) - for the 30 stands indicated by white dots in Fig. 1 versus field-estimated AGB. Although topographic slopes are small at Tapajós, i.e., $\approx 2 \pm 2^{\circ}$, their effect was calibrated out by fitting and removing a plane from the InSAR measurements over $100 \mathrm{~m} \times 100 \mathrm{~m}$ areas surrounding each study plot. This correction for slope had typically a few percent effect on coherence, up to a $10 \%$ effect on phases and about a $6 \%$ effect on biomasses estimated below. The Fourier frequency in Fig. 2 was $0.086 \mathrm{rad} / \mathrm{m}$, with corresponding vertical Fourier wavelength $\left(2 \pi / \alpha_{z}\right)$ of about $73 \mathrm{~m}$. The black curve is a second-order polynomial fit to the coherence as a function of the field-estimated AGB on the $x$-axis. The small-footprint lidar coherence is in green, with the green line a secondorder polynomial fit of coherence to the AGB. For any Fourier frequency, i.e., $\alpha_{z}$, the lidar normalized complex correlation, i.e., $\gamma_{L}\left(\alpha_{z}\right)$, is calculated by first synthesizing waveforms $w(z)$ by binning the individual returns according to height above the ground surface, i.e., $z$, and then substituting $w(z)$ for $g(z)$ in (1). Thus

$$
\gamma_{L}\left(\alpha_{z}\right)=\frac{\int_{0}^{\infty} w(z) \exp \left[i \alpha_{z} z\right] d z}{\int_{0}^{\infty} w(z) d z}
$$

Note that unlike $g(z)$, which is unknown except for its Fourier transforms, one per baseline, $w(z)$ is what lidar measures and can be directly synthesized from small-footprint measurements; all Fourier components of a waveform are accessible by using the measured $w(z)$ in the calculation on the right side of (2) for all $\alpha_{z}$ 's.

Radar principally interacts with the water in the vegetation of a forest. Because the extinction coefficient of water is six times higher at the X-band than at the L-band $(\lambda=0.2 \mathrm{~m})$ [19], and at the L-band, it is estimated to be about $0.18 \mathrm{~dB} / \mathrm{m}$ in boreal forests [20], an extinction coefficient of order $1 \mathrm{~dB} / \mathrm{m}$ could have been expected at the X-band. With an extinction that high, coupled with reports showing that the $\mathrm{C}$-band $(\lambda=0.06 \mathrm{~m})$ and higher frequencies have little sensitivity to AGB above about $50 \mathrm{Mg}$-ha ${ }^{-1}$, one might have expected that the X-band returns would originate from only the very top of the vegetation. The $\mathrm{X}$-band coherence would then result from a vertically thin layer compared with the vertical interferometric wavelength of $73 \mathrm{~m}$ and, hence, be very close to " 1 " for all AGB. Contrary to this expectation, Fig. 2 shows the InSAR coherence following a significant downward trend with field AGB, suggesting that higher AGB stands present more vertically extended scattering targets at the X-band, i.e., that the X-band radar is not interacting with just a thin layer at the top of the canopy. The decrease in coherence, of about $25 \%$, as a function of AGB is qualitatively consistent with other observations of X-band penetration [20], [21], as shown by extinction coefficients below.

The coherence from airborne small-footprint lidar in Fig. 2 shows a more extreme downward trend with AGB, suggesting that lidar penetrates more and, therefore, has a more vertically extended power profile. The magnitude of the increased attenuation by radar relative to lidar can be characterized by modeling the radar power profile, i.e., $g_{\bmod }(z)$, as an attenuated version of $w(z)$ and asking how much the lidar would have to be attenuated to give the higher coherence actually observed in the TanDEM-X data in Fig. 2. The model $g_{\bmod }(z)$, based on [13, Appendix C], is

$$
g_{\text {mod }}(z)=w(z) * \exp \left[\frac{-2 \sigma_{\text {relative }}}{\cos \theta} \int_{z}^{\infty} w_{\text {norm }}\left(z^{\prime}\right) d z^{\prime}\right]
$$

where $w_{\text {norm }}(z)$ is the lidar waveform normalized by the peak power in the $w(z)$ profile, and $\theta$ is the radar incidence angle. For a given radar-to-lidar relative extinction coefficient at the peak of the lidar profile, i.e., $\sigma_{\text {relative }}, g_{\bmod }(z)$ can be inserted into (1) with $\alpha_{z}=0.086 \mathrm{rad} / \mathrm{m}$. The value of $\sigma_{\text {relative }}$, which produces a coherence from (1) near the measured TanDEM-X coherence in Fig. 2, quantitatively describes the radar attenuation relative to that of lidar. Applying this process to the four highest AGB points in Fig. 2, for which there were both InSAR and lidar data, yielded values of $0.2-0.4 \mathrm{~dB} / \mathrm{m}$ for $\sigma_{\text {relative, }}$ with an average of $0.29 \mathrm{~dB} / \mathrm{m}$. For a primary forest stand, Fig. 3 shows an example of a radar model profile $g_{\text {mod }}(z)$ versus altitude above the surface $z$, derived from the lidar waveform in green by applying a relative extinction of $0.29 \mathrm{~dB} / \mathrm{m}$. The figure shows that the model radar profile emphasizes lidar features at higher less attenuated altitudes. It gives a qualitative idea of how lidar and InSAR profiles might compare in tropical forests, if their coherence differs as in Fig. 2. Values of X-band extinction of $0.3 \mathrm{~dB} / \mathrm{m}$ estimated in tropical forests [21] and $0.4 \mathrm{~dB} / \mathrm{m}$ in boreal forests [20] are close to the assessment using (3), if one assumes that the lidar effective extinction is close to zero, as was found in [8]. However, both references used uniform volumes (no height dependence) to estimate extinction, whereas the analysis here used $g_{\bmod }(z)$ as in (3). Comparison of the peak extinction here with other values derived by uniformvolume assumptions is therefore qualitative. The observed peak 


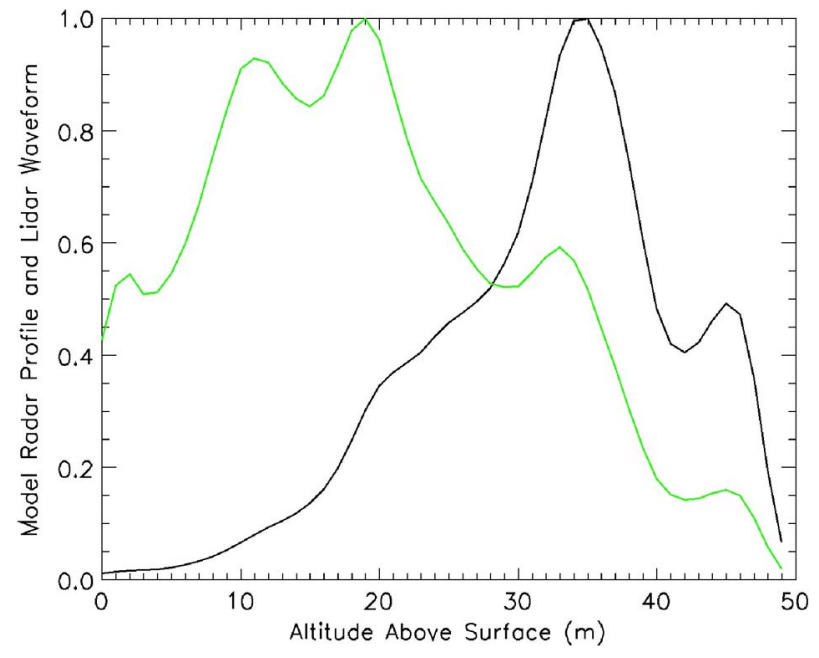

Fig. 3. Model InSAR radar power density as a function of altitude above the surface (black). The model radar profile is produced from the primaryforest lidar waveform (green) by applying (3) with a relative peak extinction coefficient of $0.29 \mathrm{~dB} / \mathrm{m}$, which makes the model profile have the same coherence as that of TanDEM-X data from the same stand.

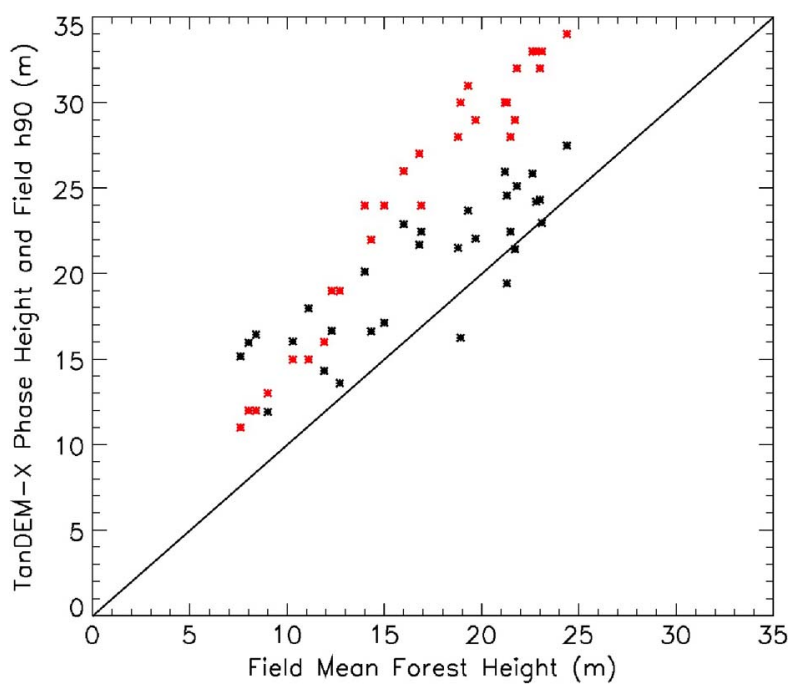

Fig. 4. TanDEM-X phase height in black, which is the InSAR phase divided by $\alpha_{z}$, the spatial Fourier frequency of the interferometer as in (1), corresponding to a vertical wavelength of $73 \mathrm{~m}$. Field measurements of $h 90$ are in red. The line is $y=x$.

extinction of $0.29 \mathrm{~dB} / \mathrm{m}$, using the model approach of (3), is only $\approx 50 \%$ higher than the L-band extinction, albeit measured in boreal forests, instead of the anticipated factor of $\approx 6$ due to water absorption. Beyond the differences in forest type and assumed canopy power profiles, that this relative extinction is lower than expected may be caused by the partial $(\approx 70 \%)$ water content in foliage [22]. It might also be caused by the clumpiness of the canopy, creating holes through which the short X-band wavelength enables penetration [23], [24]. Note that as a result of incomplete lidar coverage, the InSAR measurements extend to higher AGBs than those of lidar. The relative extinction based on the trends in Fig. 2 should be revisited with more coincident InSAR and lidar in the future.

To further demonstrate the effective penetration of TanDEM-X, Fig. 4 shows the TanDEM-X phase height in black, which is the phase in (1) divided by $\alpha_{z}$, versus the profile-averaged mean forest height from field measurements [8]. The "zero" of phase for each plot was determined by histograming the phases of $\approx 700$ pixels in each plot and taking the lowest phase to be the ground [8]. Independent ground topography was not used. For $g(z)$ symmetric about a profileweighted mean height, the phase height will be equal to that mean height, which can be demonstrated by inserting a symmetric $g(z)$ function into (1). Thus, it is expected that the phase height is some indication of the power-profile mean height. Fig. 4 also shows the field h90 height-the height beneath which is $90 \%$ of the cumulative field-estimated profile-in red. The X-band phase height is almost always higher than the field mean, the $y=x$ line, due in part to the attenuation previously mentioned. It is on average about midway between h90 and the field mean height for higher heights. There is a tendency for the phase height to be closer to h90 for short forests, which is possibly due to the extremely dense vegetation layer characteristic of early successional stands.

\section{Biomass Estimation From TANDEM-X OVER TROPICAL ForESTS}

To assess the potential performance of AGB estimation in tropical forests from TanDEM-X complex correlations, a linear model was used for AGB for the $j$ th stand, i.e., $B_{\bmod _{j}}$. As a function of the amplitude and phase of $\gamma_{I_{j}}\left(\alpha_{z}\right)$, we have

$$
B_{\bmod _{j}}=a+b\left|\gamma_{I_{j}}\right|+c \arg \left(\gamma_{I_{j}}\right)
$$

where it is understood that $j$ runs from 1 to the number of stands. In (4), $\arg \left(\gamma_{I_{j}}\right)$ is the phase of $\gamma_{I_{j}}$ for the $j$ th stand. As already noted, the vertical target extent, and presumably biomass, increases when coherence decreases and phase increases. The cost function, i.e., the reduced $\chi^{2}$, to be minimized in the fit was formed with field observations, i.e., $B_{\mathrm{obs}_{j}}$, as follows:

$$
\text { Reduced } \chi^{2} \equiv \frac{1}{N_{\text {obs }}-N_{\text {param }}} \sum_{j=1}^{N_{\text {obs }}} \frac{\left(B_{\mathrm{obs}_{j}}-B_{\bmod _{j}}\right)^{2}}{\epsilon_{\mathrm{obs}_{j}}^{2}}
$$

where $N_{\text {obs }}$ is the number of observations (i.e., 30), and $N_{\text {param }}$ is the number of parameters (i.e., 3). The reduced $\chi^{2}$ of (5) was minimized by estimating $a, b$, and $c$. The observation error, i.e., $\epsilon_{\mathrm{obs}_{j}}$, contains model components due to field measurement uncertainty and uncertainty in the algorithms in transforming from field measurements to AGB [25]. It was augmented by

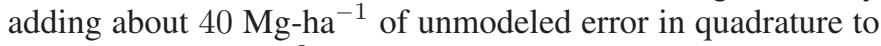
bring the reduced $\chi^{2}$ close to 1 . Although not quantitatively assessed, the empirical unmodeled error could be in part due to small misalignment between the radar coordinates and the field coordinates. Fig. 5 shows $B_{\text {mod }_{j}}$ for the best fit for $a, b$, and $c$ from (4) versus field AGB. The root mean square (RMS) of estimated AGBs about the field-about the $y=x$ dashed line-is $57{\mathrm{Mg}-\mathrm{ha}^{-1}}^{-}$and is an indication of AGB estimation performance. The fit is dominated by the phase, which alone

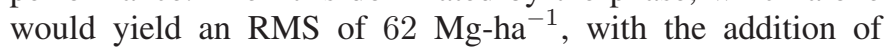
coherence reducing the RMS by an additional 7\%. Leaving one forest stand out of the fit at a time and taking the RMS 


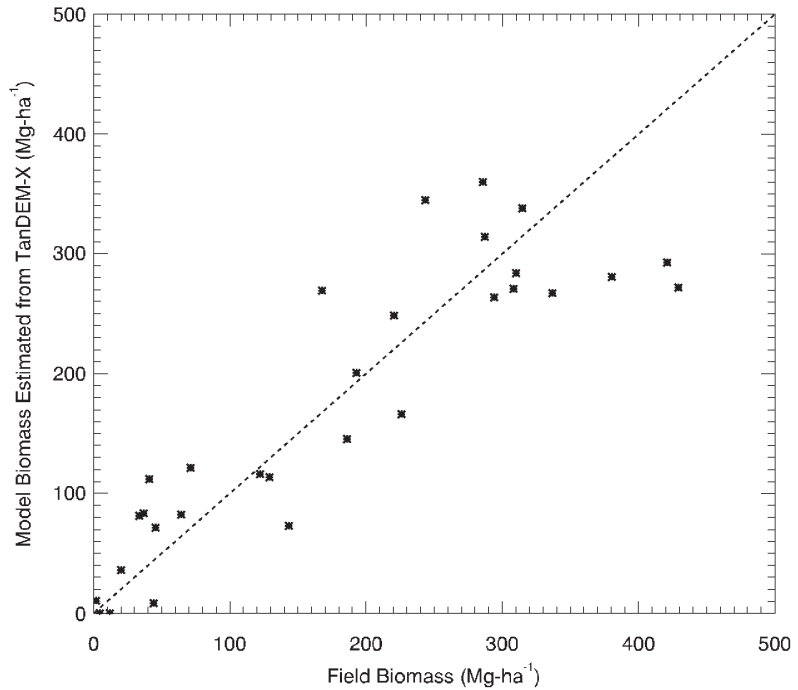

Fig. 5. Model AGB, estimated as a function of the amplitude and phase of the TanDEM-X $\gamma_{I}$, (4), versus field-estimated AGB. In (4), $a, b$, and $c$ were estimated to minimize the reduced $\chi^{2}$ in (5). The line is $y=x$.

of the resulting difference between the estimate of the one left out and the corresponding field measurement yielded a

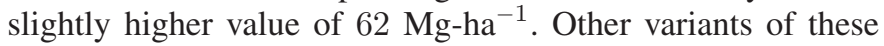
two ways of estimating performance included a model with two sets of 'b-c' parameters, each set applying to different ranges of phase height. Since phase height roughly scales with AGB, this model effectively allows for different models to be applied to low and high AGB stands. All of these variants produced RMS scatters between $52-62 \mathrm{Mg}$-ha $^{-1}$, i.e., $29 \%-35 \%$ of the mean AGB.

Preliminary AGB estimates of this letter may be improved with additional field sites, minimization of the radar-field temporal difference, and the use of more and longer baselines (higher $\alpha_{z}$ 's). The use of multiple polarizations and alternative AGB-InSAR models may also improve AGB estimation.

\section{ACKNOWLEDGMENT}

The research described in this letter was carried out in part at the Jet Propulsion Laboratory, California Institute of Technology, under a contract with the National Aeronautics and Space Administration, under the Terrestrial Ecology Program Element. The authors would like to thank the Instituto Chico Mendes de Conservação da Biodiversidade (ICMBio/MMA), the TanDEM-X staff at the German Aerospace Center (DLR) for processing and delivery of the TanDEM-X data and for technical discussions, and the Santarém Office of the Large Scale Biosphere Atmosphere Experiment in Amazonia (LBA) for providing logistical support. Lidar data were acquired with support from the United States Agency for International Development and the U.S. Department of State with the technical assistance of the Brazilian Corporation for Agricultural Research (EMBRAPA) and the U.S. Forest Service Office of International Programs. They would also like to thank A. Q. de Almeida (UFS) and E. C. de Oliveira (UFAC) for the invaluable assistance with the field acquisitions.

\section{REFERENCES}

[1] B. Saugier, J. Roy, and H. A. Mooney, "Estimations of global terrestrial productivity: Converging toward a single number?" in Terrestrial Global Productivity, J. Roy, B. Saugier, and H. A. Mooney, Eds. San Diego, CA, USA: Academic, 2001, pp. 543-557.

[2] R. A. Houghton, "How well do we know the flux of $\mathrm{CO} 2$ from land-use change?" Tellus B, vol. 62, no. 5, pp. 337-351, Nov. 2010.

[3] R. A. Houghton, "The emissions of carbon from deforestation and degradation in the tropics: Past trends and future potential," Carbon Manage., vol. 4, no. 5, pp. 539-546, Oct. 2013.

[4] Y. Pan, R. A. Birdsey, J. Fang, and D. J. Harding, "A large and persistent carbon sink in the world's forests," Science, vol. 333, no. 6045, pp. 988 993, Aug. 2011.

[5] R. A. Houghton, "Aboveground forest biomass and the global carbon balance," Global Change Biol., vol. 11, no. 6, pp. 945-958, Jun. 2005.

[6] R. A. Houghton, F. Hall, and S. J. Goetz, "Importance of biomass in the global carbon cycle," J. Geophys. Res., vol. 114, no. G2, pp. G00E03-1G00E03-13, Jun. 2009.

[7] R. N. Treuhaft et al., "Biomass estimation in a tropical wet forest using Fourier trnasforms of profiles from lidar or interferometric SAR," Geophys. Res. Lett., vol. 37, no. 23, pp. L23403-1-L23403-5, Dec. 2010.

[8] R. N. Treuhaft et al., "Vegetation profiles in tropical forests from multibaseline interferometric synthetic aperture radar, field, lidar measurements," J. Geophys. Res., vol. 114, no. D23, pp. D23110-1-D23110-16, Dec. 2009

[9] G. Krieger et al., "TanDEM-X: A satellite formation for high-resolution SAR interferometry," IEEE Trans. Geosci. Remote Sens., vol. 45, no. 11, pp. 3317-3341, Nov. 2007

[10] M. L. Imhoff, "Radar backscatter and biomass saturation: Ramifications for global biomass inventory," IEE Trans. Geosci. Remote Sens., vol. 33, no. 2, pp. 511-518, May 1995

[11] S. Viera et al., "Forest structure and carbon dynamics in Amazonian tropical rain forests," Ecosyst. Ecol., vol. 140, no. 3, pp. 468-479, Aug. 2004.

[12] J. Chave et al., "Tree allometry and improved estimation of carbon stocks and balance in tropical forests," Oecologia, vol. 145, no. 1, pp. 87-99, Aug. 2005.

[13] R. N. Treuhaft, S. N. Madsen, M. Moghaddam, and J. J. Van Zyl, "Vegetation characteristics and surface topography from interferometric radar," Radio Sci., vol. 31, no. 6, pp. 1449-1485, Nov./Dec. 1996.

[14] E. Rodriguez and J. M. Martin, "Theory and design of interferometric synthetic aperture radars," Proc. Inst. Elect. Eng. - F Radar Signal Process., vol. 139, no. 2, pp. 147-159, Apr. 1992.

[15] M. A. Lefsky, W. B. Cohen, G. G. Parker, and D. J. Harding, "Lidar remote sensing for ecosystem studies," BioScience, vol. 52, no. 1, pp. 19-30, Jan. 2002.

[16] B. E. Schutz, H. J. Zwally, C. A. Shuman, D. Hancock, and J. P. DiMarzio, "Overview of the ICESat mission," Geophys. Res. Lett., vol. 32, no. 21, pp. L21S01-1-L21S01-4, Nov. 2005.

[17] G. P. Asner, "Cloud cover in landsat observations of the Brazilian Amazon," Int. J. Remote Sens., vol. 22, no. 18, pp. 3855-3862, Dec. 2001.

[18] J. B. Drake et al., "Estimation of tropical forest structural characteristics using large-footprint lidar," Remote Sens. Environ., vol. 79, no. 2/3, pp. 305-319, Feb. 2002.

[19] U. Kaatze and V. Uhlendor, "The dielectric properties of water at microwave frequencies," Zeitschrift fur Physikalische Chemie Neue Folge, vol. 126, pp. 151-165, 1981

[20] J. Praks, O. Antropov, and M. T. Hallikainen, "Lidar-aided SAR interferometry studies in boreal forest: Scattering phase center and extinction coefficieint at X- and L-band," IEEE Trans. Geosci. Remote Sens., vol. 50, no. 10, pp. 3831-3843, Oct. 2012.

[21] I. Hajnsek, F. Kugler, S. K. Lee, and K. P. Papathanassiou, "Tropical forest parameter estimation by means of Pol-InSAR: The INDREX-II campaign," IEEE Trans. Geosci. Remote Sens., vol. 47, no. 2, pp. 481493, Feb. 2009.

[22] P. D. Coley, "Herbivory and defensive characteristics of tree species in a lowland tropical forest," Ecol. Monographs, vol. 53, no. 2, pp. 209-234, Jun. 1983.

[23] F. De Zan, G. Krieger, and P. López-Dekker, "On some spectral properties of TanDEM-X interferograms over forested areas," IEEE Geosci. Remote Sens. Lett., vol. 10, no. 1, pp. 71-75, Jan. 2013.

[24] R. N. Treuhaft et al., "Relationships between remotely sensed forest structure and biomass: Fourier structure from lidar and InSAR and penetration at microwave frequencies," Revista Brasileria de Cartografia, vol. 65, no. 4, pp. 747-755, 2013.

[25] J. Chave et al., "Error propagation and scaling for tropical forest and biomass estimates," Phil. Trans. R. Soc. Lond. B, vol. 359, no. 1443, pp. 409-420, Mar. 2004. 